\title{
Investigating the Effects of the Problem-Solving Approach among Tertiary Education Students
}

\author{
Eduard M. Albay \\ Don Mariano Marcos Memorial State University, Philippines
}

\begin{abstract}
The development of $21^{\text {st }}$-century skills that are deemed necessary for learners to excel in a knowledge-based and highly globalized society is at the core of today's education system. Towards this end, classroom practices focus on the delivery of instruction using various innovative instructional methodologies. The problem-solving approach emphasizes that important mathematics concepts and procedures can be best taught through problem-solving tasks or activities. This study utilized the problem-solving approach as supported by various collaborative strategies as an instructional intervention in teaching mathematics to first year college students and investigated its effects on the enhancement of their performance in and attitude towards College Algebra. The pretestposttest control group design using two matched groups of respondents based on their intelligence quotient scores and mathematics test scores in the University Admission Test was utilized. Ten problem-solving tasks involving routine, non-routine, and real problems were developed and provided to the experimental group. On the other hand, the conventional approach in teaching and learning was employed in the control group. Necessary were gathered through the attitude scale questionnaire and the researcher-made test and were analyzed using appropriate statistical tools. The results showed that the experimental group outperformed the control group on the bases of their posttest and mean gain scores. The experimental group also posted significant enhancement of their attitude towards college Algebra. Thus, the problem-solving approach, when applied to classroom instruction, can significantly improve students' cognitive and affective attributes in mathematics, hence indicating the effectiveness of the approach in teaching mathematics.
\end{abstract}

Keywords: Affective attributes, cognitive attributes, collaboration, problem-solving approach 


\section{Purpose of the Study}

Problem-solving is an important component of mathematics education (Căprioară, 2015). In mathematics, the term "problem-solving" refers to a systematic approach in conceptualizing and understanding a given problem, designing strategies to solve the problem, and evaluating the strategies implemented (Allen \& Graden, 2002). It involves mathematical tasks that have the potential to provide intellectual challenges for enhancing students' mathematical understanding and to develop their ability to find meaningful solutions to solve problems using effective and timely strategies (Karabacak et al., 2015; Yavuz \& Erbay, 2015).

The problem-solving approach, also referred to as teaching through problemsolving, focuses on teaching mathematical topics through problem-solving contexts and inquiry-oriented environments, which are characterized by the teacher helping the students construct a deep understanding of mathematical ideas and processes by engaging them in doing mathematics: creating, conjecturing, exploring, testing, and verifying (Cai \& Lester, 2010).

The use of the problem-solving approach in teaching can facilitate the development and acquisition skills, knowledge, and expertise that are essential in the $21^{\text {st }}$ century society (Fong et al., 2014; Dass, 2014). Among these essential $21^{\text {st }}$-century skills are collaboration and problem-solving.

Thus, this true experimental study using the pretest-posttest control group design was conducted to investigate the effects of the problem-solving approach as an alternative instructional strategy in teaching mathematics to the enhancement of performance and attitude of first-year college students in College Algebra. Specifically, this study determined the performance of the experimental group and the control group before and after the experiment using a validated researcher-made test. The attitudes of the groups towards the subject College Algebra before and after the experiment were also measured using an attitudinal questionnaire. In addition, the study compared the posttest scores and mean gain scores of the two groups of the respondents. The attitudes of the experimental and control groups before and after the experiment were also compared. The results of the comparative analyses of the respondents' posttest scores, mean gain scores, and attitudes towards College Algebra provided pieces of evidence about the effects of the use of the problem-solving approach to the identified dependent variables of this study.

\section{Methodology}

The true experimental research using pretest-posttest control group design was employed to examine and compare the performance in and attitude towards College Algebra of first-year college students. This study involved two classes of first-year tertiary education students from two distinct curricular programs of the Don Mariano Marcos Memorial State University, Philippines, who are enrolled in College Algebra and who are under the direct supervision of the researcher. The students from the two classes 
were paired on the basis of their Intelligence Quotient (IQ) scores and mathematics test scores in the University Admission Test, which are available at the University Guidance Office.

Twenty pairs of students with equivalent IQ and mathematics test scores formed the respondents of the study. The respondents have varied levels of performances, categorized as low, average, and high, in the university admission test to ensure even distribution of respondents for each class in terms of cognitive abilities. The assignment of the experimental group and the control group was done randomly through the tossing of a coin. The students who were not selected as respondents underwent the same teaching and learning process as those considered respondents following the teaching methodology assigned to their class.

The problem-solving approach was implemented to the experimental group, together with collaborative strategies such as simple jigsaw, structured problem-solving, guided collaboration, focused listing, and paired annotations.

To fulfill the objectives of the study, 10 mathematical problem-solving tasks involving routine, non-routine, and real problems in various topics in the approved course syllabus in College Algebra were developed by the researcher. The mathematical problems provided to the experimental group satisfied the following criteria (Lappan \& Phillips, 1998): involve useful mathematics concepts and processes, require higher-level thinking and problem solving, have various solutions, allow different strategies and decisions to be taken and defended by the students, encourage students' active engagement and discourse, have a connection with other important mathematical ideas, and promote skillful use of mathematics. The problem-solving tasks provided a platform for collaborative work for the group. Moreover, the 20 respondents were distributed to different groups to work with the non-respondents in the class. The role of the researcher was to provide just enough information to establish the background of the tasks, to accept correct or wrong answers in a non-evaluative way, and to intervene in the problemsolving process when appropriate and necessary.

The control group, on the other hand, was taught using the conventional method of teaching where the presentation of concepts and mathematical processes was done through lecture and demonstration methods. The role of the students was to listen to the discussion and to answer questions raised by the researcher. The classroom instruction started with the presentation of the lesson, discussion of relevant concepts, demonstration of mathematical procedures, practicing the concepts and skills learned through board activities and oral recitations, and assessing students' learning by providing them with written activities. Most of the evaluative activities provided were accomplished individually. Group activities were also implemented, but such did not follow a definite structure for group work.

The experimental study was conducted for a period of 10 weeks, with three hours of meeting each week. Both the experimental and control groups do not have any knowledge as to the conduct of the experimental study. 


\section{Results}

\section{Performance in College Algebra}

Table 1 indicates the performances in College Algebra of the two groups of respondents before and after the conduct of this study based on the results of the pretest and posttest. It is reflected from the table that $65 \%$ of the experimental group and $70 \%$ of the control group obtained pretest scores that cluster around the 0 to 20 score range. Also, $35 \%$ and $30 \%$ of the experimental group and control group, respectively, scored more than 20 in the pretest.

Moreover, there are slight differences in the pretest scores of the two groups. However, there are notable comparisons between the performances in College Algebra of the two groups that can be observed in their posttest scores.

For the experimental group, the percentage of respondents who got a score from 0 to 20 decreased by $40 \%$, from $65 \%$ in the pretest to $25 \%$ in the posttest. In the same score range, the control group posted a reduction rate of only $10 \%$, from $70 \%$ to 60 percent, in the pretest and posttest, respectively.

Table 1. Performance of the Respondents in the Pretest and Posttest

\begin{tabular}{|c|c|c|c|c|c|c|c|c|}
\hline \multirow{4}{*}{$\begin{array}{c}\text { Score } \\
\text { Rang } \\
\text { e }\end{array}$} & \multicolumn{4}{|c|}{ Experimental Group } & \multicolumn{4}{|c|}{ Control Group } \\
\hline & \multicolumn{2}{|c|}{ Pretest } & \multicolumn{2}{|c|}{ Posttest } & \multicolumn{2}{|c|}{ Pretest } & \multicolumn{2}{|c|}{ Posttest } \\
\hline & Frequenc & Percentag & Frequenc & Percentag & Frequenc & Percentag & Frequenc & Percentag \\
\hline & $\mathrm{y}$ & $\mathrm{e}$ & $\mathrm{y}$ & $\mathrm{e}$ & $\mathrm{y}$ & $\mathrm{e}$ & $\mathrm{y}$ & $\mathrm{e}$ \\
\hline $0-10$ & 1 & 5.00 & 0 & 0.00 & 1 & 5.00 & 0 & 0.00 \\
\hline $11-20$ & 12 & 60.00 & 5 & 25.00 & 13 & 65.00 & 12 & 60.00 \\
\hline $21-30$ & 5 & 25.00 & 3 & 15.00 & 4 & 20.00 & 5 & 25.00 \\
\hline $31-40$ & 2 & 10.00 & 11 & 55.00 & 2 & 10.00 & 2 & 10.00 \\
\hline $41-50$ & 0 & 0.00 & 1 & 5.00 & 0 & 0.00 & 1 & 5.00 \\
\hline $\begin{array}{l}\text { Mean } \\
\text { Gain }\end{array}$ & \multicolumn{4}{|c|}{7.70} & \multicolumn{4}{|c|}{2.75} \\
\hline
\end{tabular}

The experimental group recorded an increase of $40 \%$ in the percentage of respondents, which obtained scores of at least 20 , that is, from $35 \%$ in the pretest to $75 \%$ in the posttest. For the control group, an increase of only $10 \%$ in the percentage of respondents who obtained such scores was noted.

In terms of mean gain score, which refers to the average of the differences between the posttest and pretest scores, the experimental group garnered an average increase of 7.70 in their posttest scores as compared to the 2.75 average gain scores obtained by the control group.

When the posttest and mean gain scores of the two groups were compared, the results indicated $p$-values equivalent to 0.000 and 0.011 , respectively. These statistics show that the performances of the two groups are significantly different. Although both groups improved in the posttest, the tests of difference employed to the posttest and mean gain scores confirmed that the experimental group obtained higher scores and performed better than the control group. 


\section{Attitude towards College Algebra}

In Table 2, it can be observed that both the control group and the experimental group conveyed a neutral attitude towards College Algebra before the experimentation, with weighted means of their responses equal to 3.19 and 3.12 , respectively.

Further, the table reflects that the experimental group indicated a neutral attitude to 20 indicators. These include the indicators that convey ideas about the importance of the subject College Algebra, the topics and their applications to real life, the rules involved in the subject, and being comfortable, happy, and excited about College Algebra.

Table 2. Attitude of the Respondents Towards College Algebra

\begin{tabular}{|c|c|c|c|c|c|c|c|c|}
\hline \multirow{3}{*}{ Indicators } & \multicolumn{4}{|c|}{ Experimental Group } & \multicolumn{4}{|c|}{ Control Group } \\
\hline & \multicolumn{2}{|c|}{ Pre } & \multicolumn{2}{|c|}{ Post } & \multicolumn{2}{|c|}{ Pre } & \multicolumn{2}{|c|}{ Post } \\
\hline & WM & VD & WM & VD & WM & VD & WM & VD \\
\hline College Algebra is stimulating and interesting. & 3.55 & $\mathrm{~F}$ & 4.45 & VF & 3.8 & $\mathrm{~F}$ & 4.00 & $\mathrm{~F}$ \\
\hline College Algebra is enjoyable, and fun. & 3.90 & $\mathrm{~F}$ & 4.25 & VF & 3.85 & $\mathrm{~F}$ & 4.15 & $\mathrm{~F}$ \\
\hline $\begin{array}{l}\text { The topics and their applications to real life are } \\
\text { fascinating. }\end{array}$ & 2.90 & $\mathrm{~N}$ & 4.05 & $\mathrm{~F}$ & 2.50 & $\mathrm{U}$ & 1.85 & $\mathrm{U}$ \\
\hline This subject makes me feel comfortable. & 3.15 & $\mathrm{~N}$ & 3.90 & $\mathrm{~F}$ & 2.90 & $\mathrm{~N}$ & 3.60 & $\mathrm{~F}$ \\
\hline $\begin{array}{l}\text { I am able to think clearly when working with } \\
\text { this subject. }\end{array}$ & 3.60 & $\mathrm{~F}$ & 4.05 & $\mathrm{~F}$ & 3.20 & $\mathrm{~N}$ & 3.30 & $\mathrm{~N}$ \\
\hline I enjoy this subject very much. & 2.90 & $\mathrm{~N}$ & 4.00 & $\mathrm{~F}$ & 3.35 & $\mathrm{~N}$ & 3.45 & $\mathrm{~F}$ \\
\hline It encourages me to think and try harder. & 3.60 & $\mathrm{~F}$ & 4.40 & VF & 3.80 & $\mathrm{~F}$ & 4.00 & $\mathrm{~F}$ \\
\hline $\begin{array}{l}\text { I understand this subject because the teacher } \\
\text { explains well. }\end{array}$ & 3.60 & $\mathrm{~F}$ & 4.55 & VF & 3.30 & $\mathrm{~N}$ & 3.70 & $\mathrm{~F}$ \\
\hline I do well in this subject. & 2.40 & $\mathrm{U}$ & 3.95 & $\mathrm{~F}$ & 2.50 & $\mathrm{U}$ & 2.25 & $\mathrm{U}$ \\
\hline I feel excited to work with College Algebra. & 2.85 & $\mathrm{~N}$ & 3.45 & $\mathrm{~N}$ & 2.80 & $\mathrm{~N}$ & 3.05 & $\mathrm{~N}$ \\
\hline I feel at ease in this subject. & 3.15 & $\mathrm{~N}$ & 3.90 & $\mathrm{~F}$ & 3.15 & $\mathrm{~N}$ & 3.15 & $\mathrm{~N}$ \\
\hline I learn to think logically in this subject. & 3.05 & $\mathrm{~N}$ & 4.55 & $\mathrm{VF}$ & 3.50 & $\mathrm{~F}$ & 3.40 & $\mathrm{~F}$ \\
\hline This subject makes me feel I am an expert. & 2.55 & $\mathrm{U}$ & 3.25 & $\mathrm{~N}$ & 2.85 & $\mathrm{~N}$ & 2.40 & $\mathrm{U}$ \\
\hline I find this subject easy to understand. & 2.95 & $\mathrm{~N}$ & 4.05 & $\mathrm{~F}$ & 2.55 & $\mathrm{U}$ & 2.30 & $\mathrm{U}$ \\
\hline This Mathematics subject is important to me. & 2.90 & $\mathrm{~N}$ & 3.90 & $\mathrm{~F}$ & 2.85 & $\mathrm{~N}$ & 2.05 & $\mathrm{U}$ \\
\hline I am happy in my College Algebra class. & 2.95 & $\mathrm{~N}$ & 3.80 & $\mathrm{~F}$ & 3.55 & $\mathrm{~F}$ & 3.80 & $\mathrm{~F}$ \\
\hline $\begin{array}{l}\text { I am confident that I can solve problems in } \\
\text { College Algebra. }\end{array}$ & 3.05 & $\mathrm{~N}$ & 4.20 & VF & 3.5 & $\mathrm{~F}$ & 3.60 & $\mathrm{~F}$ \\
\hline $\begin{array}{l}\text { This subject develops my ability to think and } \\
\text { reason out accurately. }\end{array}$ & 2.95 & $\mathrm{~N}$ & 4.35 & VF & 3.15 & $\mathrm{~N}$ & 3.95 & $\mathrm{~F}$ \\
\hline College Algebra is my most loved subject. & 3.15 & $\mathrm{~N}$ & 4.35 & VF & 3.20 & $\mathrm{~N}$ & 3.80 & $\mathrm{~F}$ \\
\hline I love this subject even if my teacher is strict. & 2.90 & $\mathrm{~N}$ & 4.40 & VF & 3.15 & $\mathrm{~N}$ & 3.90 & $\mathrm{~F}$ \\
\hline College Algebra is challenging. & 3.25 & $\mathrm{~N}$ & 4.40 & $\mathrm{VF}$ & 2.95 & $\mathrm{~N}$ & 3.10 & $\mathrm{~N}$ \\
\hline I do like the rules used in this subject. & 3.15 & $\mathrm{~N}$ & 3.85 & $\mathrm{~F}$ & 3.35 & $\mathrm{~N}$ & 4.05 & $\mathrm{~F}$ \\
\hline I like working on exercises and assignments. & 2.95 & $\mathrm{~N}$ & 4.25 & $\mathrm{VF}$ & 3.60 & $\mathrm{~F}$ & 3.85 & $\mathrm{~F}$ \\
\hline This is my favorite subject. & 2.95 & $\mathrm{~N}$ & 3.55 & $\mathrm{~F}$ & 2.75 & $\mathrm{~N}$ & 3.55 & $\mathrm{~F}$ \\
\hline $\begin{array}{l}\text { The activities in this subject make me } \\
\text { understand the lesson better. }\end{array}$ & 3.90 & $\mathrm{~F}$ & 4.20 & VF & 3.35 & $\mathrm{~N}$ & 4.05 & $\mathrm{~F}$ \\
\hline
\end{tabular}




\begin{tabular}{|c|c|c|c|c|c|c|c|c|}
\hline This subject is not an ordinary one. & 3.65 & $\mathrm{~F}$ & 3.95 & $\mathrm{~F}$ & 3.55 & $\mathrm{~F}$ & 3.80 & $\mathrm{~F}$ \\
\hline College Algebra is worth studying. & 2.95 & $\mathrm{~N}$ & 3.65 & $\mathrm{~F}$ & 3.00 & $\mathrm{~N}$ & 3.10 & $\mathrm{~N}$ \\
\hline The rules and processes are easy to follow. & 3.20 & $\mathrm{~N}$ & 4.15 & $\mathrm{~F}$ & 2.65 & $\mathrm{~N}$ & 2.75 & $\mathrm{~N}$ \\
\hline I enjoy analyzing College Algebra problems. & 2.45 & $\mathrm{U}$ & 4.25 & $\mathrm{VF}$ & 3.40 & $\mathrm{~F}$ & 3.50 & $\mathrm{~F}$ \\
\hline $\begin{array}{l}\text { I feel a definite positive reaction towards } \\
\text { College Algebra. }\end{array}$ & 3.15 & $\mathrm{~N}$ & 4.05 & $\mathrm{~F}$ & 3.70 & $\mathrm{~F}$ & 3.95 & $\mathrm{~F}$ \\
\hline Average weighted mean & 3.12 & $\mathbf{N}$ & 4.07 & $\mathbf{F}$ & 3.19 & $\mathbf{N}$ & 3.38 & $\mathbf{N}$ \\
\hline $\begin{array}{l}\text { Legend: } \\
\qquad \begin{array}{l}\mathrm{WM}=\text { Average weighted Mean } \\
\mathrm{VD}=\text { Verbal Description } 5.00\end{array}\end{array}$ & & & \multicolumn{6}{|c|}{$\begin{array}{ll}\text { Scale } & \text { Verbal Description } \\
4.20-5.00 & \text { Very Favorable (VF) } \\
3.40-4.19 & \text { Favorable (F) } \\
2.60-3.39 & \text { Neutral (N) } \\
1.80-2.59 & \text { Unfavorable (U) }\end{array}$} \\
\hline
\end{tabular}

They also rated with a neutral attitude the indicators that state that College Algebra helps them think logically and reason out accurately, and being interested and confident in working with exercises and assignments.

Also, the experimental group rated with an unfavorable attitude the indicators "I do well in this subject," "The subject makes me feel I am an expert," and "I enjoy analyzing College Algebra problems." Seven of the indicators garnered a favorable attitude from the experimental group, and these include the ideas that College Algebra is stimulating, interesting, fun; it makes them think clearly and encourages them to try harder; and the activities and the explanation of the teacher make them understand the subject better.

For the control group, 17 indicators were rated with neutral attitude, including those that state that the subject makes them feel comfortable and excited to learn; they are able to think clearly when working with the subject; the teacher is strict; College Algebra is worth studying; and the rules are easy to follow. The group also indicated a neutral attitude on the indicators stating that the topics and their applications to real-life are fascinating; they do well in the subject; and College Algebra is easy to understand. In addition, 10 indicators were rated with a favorable attitude by the control group.

Like the experimental group, the control group also favored the idea that the subject is stimulating, fun, interesting, and extraordinary; and it encourages them to think and try harder. The group also conveyed a favorable attitude on the indicators, which indicate that they learn to think logically in this subject; they are confident and they love to solve math problems; and they feel a positive reaction towards College Algebra.

After the experiment, it can be noted that the attitude of the experimental group towards College Algebra improved from neutral to favorable, as evident in the average weighted mean of their responses equal to 4.07. On the other hand, the control group remained consistent with its neutral attitude towards College Algebra after the experiment.

The study also looked into how the respondents rated the different indicators. From the 30 indicators in the questionnaire, the experimental group rated two indicators with a neutral attitude, 15 with a favorable attitude, and 13 with a very favorable attitude. After the experiment, the group highly agreed that College Algebra is interesting, 
stimulating, and fun. Although the group stated that they highly favor the idea that the subject is challenging, they highly recognize the importance of the subject in acquiring the ability to think logically and to reason out accurately. The subject also allowed them to think critically by pushing them to work and think harder. Also, the competence of the teacher helped them gain a positive attitude towards College Algebra. Further, the experimental group agreed that the subject has fascinating applications to real life.

For the control group, five indicators were rated with an unfavorable attitude, six with a neutral attitude, and 19 with a favorable attitude after the conduct of the experiment. The control group still favorably viewed College Algebra as a fun, interesting, and stimulating subject, and they positively recognized the potential of the subject to push them to work and try harder. They agreed that College Algebra enabled them to develop skills like reasoning and logical thinking. However, the respondents in the control group do not view College Algebra as an important subject as they do not recognize its relevant applications to real life.

The study also compared the attitudes of the groups of respondents before and after the experiment. Test results showed a significant difference between each group's attitude towards mathematics before and after the experiment and indicated that only the experimental group posted a significant improvement or change in their attitude with a $p$ value equal to 0.000 . The improvement in the attitude of the control group towards College Algebra, on the other hand, was not sufficient to claim a significant change or enhancement in their attitude as viewed in the obtained $p$-value of 0.195 .

\section{Conclusions/Implications/Recommendations}

The data and the results of the analyses conducted on the performance and attitude of the respondents provide scientific evidence about the potential of the problemsolving approach to cause a significant improvement in the cognitive and affective attributes of students in College Algebra. It has been shown in this study that teaching through problem-solving develops the skills of students to prosper in a self-regulatory and problem-centered learning environment. The use of routine, non-routine, and real problems delivered learning opportunities and provided direct experiences for the experimental group to learn and understand mathematics by applying both structured and non-structured methods of solving real-life problems. This fostered the development of the students' skills in utilizing previously learned concepts, critically evaluating the given variables and their interrelationships, constructing new knowledge by sourcing out information from various content areas, selecting appropriate ways of representing or modeling the given problems, generating and devising a myriad of viable strategies and approaches towards achieving the goals of the tasks, evaluating these planned solutions, reflecting on their applied cognitive and metacognitive strategies, and effectively communicating their solutions using relevant media and tools. True to the ideas of Gur and Korkmaz (2003) and Altun (2008, as reported by Yavuz and Erbay, 2015), allowing students to solve mathematically rich problems enable them to gain meaningful experiences in solving mathematics problems and in selecting appropriate strategies to 
solve the problems. Therefore, posing mathematically rich problems can be an effective means of learning and understanding mathematics, hence resulting in a better performance in the subject (Căprioară, 2015).

The six stages of the problem-solving process (Organisation for Economic Cooperation and Development, 2014) laid down a definitive method for presenting the experimental group's solutions to the problem-solving tasks. By correctly identifying the given variables and the unknown, the students were able to determine further knowledge that they need to acquire by carefully considering relevant contents from numerous resources and through social interactions. A connection between previously learned concepts and newly acquired knowledge was then established, thereby making them proficient in constructing visual representations or models for the problems. By exploration and manipulation of the models developed, the students were deeply and actively engaged in generating, testing, refining, and justifying mathematical conjectures, which guided their planned strategies and solutions. The collaborative examination and reflection on the solutions generated allowed the members of each group in the experimental group to scrutinize the correctness, completeness, and accuracy of their solutions. In cases where inconsistencies are noted, the group refined their solutions and presented them in ways that are comprehensible to the rest of the experimental group. Because every member was involved in the entire process of the problem-solving tasks, each member gained the necessary confidence in explaining their approaches or strategies and in justifying their solutions. Although the control group was given the same problem-solving tasks to accomplish, the learning environment characterized by the conventional method of mathematics teaching did not provide essential conditions, allowing for deeper exploration and investigation of the problem tasks at hand.

As teaching through problem-solving promotes a collaborative nature of the learning environment, the experimental group achieved a higher level of conceptual understanding, critical thinking skills, and problem-solving skills through their active engagement in the discourse and exploration process (Gokkurt et al., 2012). This feature of the problem-solving approach was highly significant, especially when the experimental group dealt with the open problems that prompted them to demonstrate effective communication, logical thinking, reasoning skills, and handling diverse and varied perspectives. Although the members of each group were provided with opportunities to listen to different perspectives and to challenge the ideas of the other members, each was given a chance to present and defend their conceptual frameworks. All the members in the experimental group were compelled to explain how their ideas work based on the given information in the problems and to justify what prompted them to generate a particular conclusion. In short, they were encouraged to explain their thinking to their group. Thus, the problem-solving approach provided opportunities for the students to hone valuable problem-solving skills by formulating their ideas, discussing them with their group members, receiving immediate feedback, and responding to questions and comments (Laal \& Ghodsi, 2012) through which they were able to refine, combine, and modify knowledge they already learned (Cai \& Lester, 
2010). Further, the approach highlighted the importance of working as a team and demonstrating effective communication to solve a problem-solving task (Abdullah et al., 2010); Duch et al., 2001). Such an active exchange of ideas did not occur in the class of the control group as the conventional method of teaching capitalized on individual learning and seldom provided platforms for group work.

Meanwhile, the support and assistance a member received from the other members of the group also play a crucial role in the implementation of the problemsolving approach in mathematics teaching. It is essential to create a learning environment where asking for necessary support from advance members or providing the needed assistance to challenged members is an integral component of learning and understanding mathematics. Therefore, Vygotsky's idea of zone of proximal development and scaffolding (1978) also contributed to the results of the study based on the performance of the experimental group as compared to the control group's performance. The different collaborative strategies implemented along with the approach required the members of the group to assess each other's learning and mastery of the relevant concepts and mathematical processes. The scaffolding strategies employed by each group provided the needed support and assistance to the struggling members. In their attempt to solve the problem tasks, the students in the experimental group made sure that they meet the level of their members, they provided opportunities for clarifications, and they maintained open communication to address any difficulties that the members encounter in the course of accomplishing the goal of the tasks. This kind of supportive learning environment prevailed and dominated the classroom of the experimental group in the entire duration of the experiment, producing students who can effectively implement the six stages of the problem-solving process. As anyone from each group can be chosen to present their respective outputs with or without help from the other members, this necessitated all the members to acquire the necessary understanding and mastery to comprehensively discuss their group's output and to substantially answer questions from the class. Indeed, the high level of interaction and interdependence assisted the students in acquiring deep understanding and mastery of the concepts and mathematical processes. Thus, the experimental group developed mathematical power that enabled them to solve mathematical problems on their own during the administration of the posttest. The active support provided through scaffolding ensured that all students of the experimental group had gained the necessary competencies to solve mathematical problems independently. This enabled the group to record higher scores in the posttest and, thus, outperformed the control group.

Moreover, the problem-solving approach developed the students' positive attitude towards mathematics as a result of the supportive learning environment of the approach where collaboration is valued rather than competition, which is most likely to occur in an individualistic approach to teaching mathematics.

Considering that the respondents in the experimental group had to work collaboratively since the start of the experiment, the interactions happened regularly; hence they came to know each other better, and they were able to build a healthy, friendly, and helping relationship. They are free to seek help from their peers by asking 
questions or requesting explanations. Although the low performers gained conceptual understanding and acquired problem-solving skills from the high performing members, the latter also became more committed to discuss and explain concepts, processes, and mathematical ideas in order to address the difficulties encountered by the former. The approach also highlighted the role of the high performing members, particularly on taking responsibility not only of their own learning but also the learning of their low performing members. Moreover, the active exchange of ideas and supportive environment created by the students nurtured positive feelings that consequently increased their interests towards learning.

Being engaged in collaborative problem-solving tasks enabled the experimental group to develop patience, perseverance, disposition, and motivation to learn and understand mathematics. The strong support of the high performing members led the low performing members to develop a better understanding of the problems and to explore and focus on the meaning of the problems. One of the observed behaviors of the experimental group was the satisfaction and happiness they derived from discovering the solutions of the problem-solving tasks.

Additionally, the respondents of the experimental group were observed to be more confident to present their output to the class, thinking that it was a product of the collective efforts of the group. This, in turn, helped the students to eliminate their fear towards the subject and their anxiety in working with College Algebra problems. By working as a group, it transformed them from passive listeners and information receivers to active, well-engaged learners, and problem solvers (Ali et al., 2010). As a result, the experimental group gradually built confidence in working with the problem-solving tasks, exercises, and other activities; hence the development of mathematical power that contributed to the attainment of a more positive attitude towards College Algebra.

The role of the researcher in the problem-solving process also played a vital role in the improvement of the experimental group's performance and attitude. The presence of the researcher enabled the students to instantly acquire guidance in situations where they were stuck. Although instructions as to how the students should work on the problems cannot be given, the insightful questions that the researcher asked served as a springboard for students' reflection about their work or the process they applied. This allowed them to integrate essential modifications to their strategies, hence leading them to the solutions of the tasks.

To sum up, the problem-solving approach can cause significant improvement to the cognitive and affective attributes of students in tertiary education. When effectively implemented, the approach can enhance students' academic achievement in mathematics. Equally important, it can also strengthen or reinforce a more positive attitude towards the subject. The use of the approach in teaching mathematics also provides effective learning conditions that allow students to develop essential $21^{\text {st }}$-century skills.

Although the results of the study contribute to the existing body of knowledge on the use of a problem-solving approach in mathematics education, more extensive research studies involving the use of the approach need to be conducted. Future researchers may explore on the skills and competencies of mathematics teachers that are considered vital 
for the effective implementation of the problem-solving approach. As this study only considered the results of the test and the attitudinal questionnaire, researchers may consider analyzing students' interaction and communication strategies while attempting to solve the problem-solving tasks and investigate their effects on the performance of the students. They may also explore the approaches and strategies devised by the students in accomplishing the problem-solving tasks, which may lead to the creation of a problemsolving model that is distinct in a problem-solving approach mathematics classroom.

\section{Acknowledgment}

My sincerest gratitude is given to the administrators of the Don Mariano Marcos Memorial State University for providing opportunities and funding support for the completion of this research study.

I thank my wife - Ruby, children - Rapa and Rayied, parents - Florentino and Josefina, and siblings Fe, Flordeliza, Grace, Freddie, and JR.

I am forever grateful to God Almighty, who made all things possible.

\section{References}

Abdullah, N. I., Tarmizi, R. A., \& Abu, R. (2010). The effects of problem based learning on mathematics performance and affective attributes in learning statistics at form four secondary level. Procedia-Social and Behavioral Sciences, 8, 370-376. https://doi.org/10.1016/j.sbspro.2010.12.052

Ali, R., Akhter, A., \& Khan, A. (2010). Effect of using problem solving method in teaching mathematics on the achievement of mathematics students. Asian Social Science, 6(2), 67.

Allen, S. J., \& Graden, J. L. (2002). Best practices in collaborative problem solving for intervention design. In A. Thomas \& J. Grimes (Eds.), Best practices in school psychology IV (pp. 565-582). National Association of School Psychologists. https://psycnet.apa.org/record/2006-03715-038

Cai, J., \& Lester, F. K. (2010). Why is teaching with problem solving important to student learning: Problem solving (Research Brief). National Council of Teachers of Mathematics.

https://www.nctm.org/uploadedFiles/Research_and_Advocacy/research_brief_and _clips/Research_brief_14_-_Problem_Solving.pdf

Căprioară, D. (2015). Problem solving-purpose and means of learning mathematics in school. Procedia-Social and Behavioral Sciences, 191, 1859-1864. 
Dass, R. (2014). Literature and the 21st century learner. Procedia-Social and Behavioral Sciences, 123, 289-298. https://doi.org/10.1016/j.sbspro.2014.01.1426

Duch, B. J., Groh, S. E., \& Allen, D. E. (Eds.). (2001). The power of problem-based learning: A practical "how to" for teaching undergraduate courses in any discipline. Stylus Publishing, LLC. https://tinyurl.com/y3qyx3pb

Fong, L. L., Sidhu, G. K., \& Fook, C. Y. (2014). Exploring 21st century skills among postgraduates in Malaysia. Procedia-Social and Behavioral Sciences, 123, 130138. https://doi.org/10.1016/j.sbspro.2014.01.1406

Gur, H. \& Korkmaz, E. (2003). Ilkogretim 7. sinif ogrencilerinin problem ortaya atma becerilerinin belirlenmesi. 7. Matematik Sempozyumu Sergi ve Senlikleri. 8 Aralık 2011 tarihinde http://www.matder.org.tr/ adresinden alinmistir

Karabacak, K., Nalbant, D., \& Topçuoğlu, P. (2015). Examination of teacher candidates' problem solving skills according to several variables. Procedia-Social and Behavioral Sciences, 174, 3063-3071. https://doi.org/10.1016/j.sbspro.2015.01.1099

Laal, M., \& Ghodsi, S. M. (2012). Benefits of collaborative learning. Procedia-Social and Behavioral Sciences, 31, 486-490. https://doi.org/10.1016/j.sbspro.2011.12.091

Lappan, G., \& Phillips, E. (1998). Teaching and Learning in the Connected Mathematics Project. In L. Leutzinger (Ed.), Mathematics in the middle (pp. 83-92). National Council of Teachers of Mathematics

Organisation for Economic Co-operation and Development (OECD). (2014). PISA 2012 results: Creative problem solving: Students' skills in tackling real-life problems (Volume V). OECD.Pacific Policy Research Center. (2010). 21st century skills for students and teachers. Kamehameha Schools, Research \& Evaluation Division. $\quad$ Retrieved March 19, 2017 from http://www.ksbe.edu/_assets/spi/pdfs/21_century_skills_full.pdf

Yavuz, G., \& Erbay, H. N. (2015). The analysis of pre-service teachers' beliefs about mathematical problem solving. Procedia-Social and Behavioral Sciences, 174, 2687-2692.

Vygotsky, L.S. (1978). Mind in Society. Cambridge, MA: Harvard University Press. 